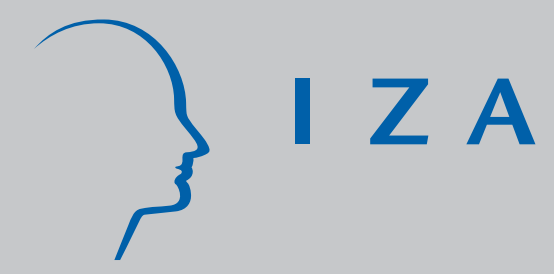

IZADP No. 4096

Integration, Labor Market Regulation, Lobbying and Technological Change

Tapio Palokangas

March 2009 


\title{
Integration, Labor Market Regulation, Lobbying, and Technological Change
}

\author{
Tapio Palokangas \\ University of Helsinki, \\ HECER, IIASA and IZA
}

Discussion Paper No. 4096

March 2009

\author{
IZA \\ P.O. Box 7240 \\ 53072 Bonn \\ Germany \\ Phone: $+49-228-3894-0$ \\ Fax: +49-228-3894-180 \\ E-mail: iza@iza.org
}

Any opinions expressed here are those of the author(s) and not those of IZA. Research published in this series may include views on policy, but the institute itself takes no institutional policy positions.

The Institute for the Study of Labor (IZA) in Bonn is a local and virtual international research center and a place of communication between science, politics and business. IZA is an independent nonprofit organization supported by Deutsche Post Foundation. The center is associated with the University of Bonn and offers a stimulating research environment through its international network, workshops and conferences, data service, project support, research visits and doctoral program. IZA engages in (i) original and internationally competitive research in all fields of labor economics, (ii) development of policy concepts, and (iii) dissemination of research results and concepts to the interested public.

IZA Discussion Papers often represent preliminary work and are circulated to encourage discussion. Citation of such a paper should account for its provisional character. A revised version may be available directly from the author. 
IZA Discussion Paper No. 4096

March 2009

\section{ABSTRACT \\ Integration, Labor Market Regulation, Lobbying, and Technological Change*}

This paper examines an economic union where oligopolistic firms produce by skilled and unskilled labor and do in-house R\&D by skilled labor. The planner of the union accepts new members to the union, regulates the labor market through a minimum wage for unskilled labor and supports firms by taxation. Firms and workers lobby the planner for prospective policy. It is shown that in the political equilibrium small unions regulate the labor market but do not support firms, while large unions deregulate the labor market and support firms.

JEL Classification: F15, J50, O40

Keywords: economic integration, minimum wage, market power, endogenous technological change

Corresponding author:

Tapio Palokangas

Department of Economics

P.O. Box 17 (Arkadiankatu 7)

FIN-00014 University of Helsinki

Finland

E-mail: Tapio.Palokangas@helsinki.fi

*Financial support from the Yrjö Jahnsson Foundation is gratefully acknowledged. I am also grateful to Arkady Kryazhimskiy and Pertti Haaparanta for constructive comments. 


\section{Introduction}

In the years 1975-2000, the US and UK experienced sharp increases in wage inequality and rapid labor market deregulation. Aghion et al. (2001) explain these phenomena by skill-biased technological change. In this paper, I offer an alternative explanation through political economy as follows: With a little product market competition, there is a political pressure to redistribute income through labor market regulation. Economic integration, however, intensifies product market competition and leads to stagnation where slow economic growth is associated with unemployment. This creates political pressure to support firms and de-regulate the labor market.

This paper models economic integration as a political process. I consider an economic union, where firms are subject to oligopolistic competition, but attempt to improve their productivity through in-house R\&D. I characterize the policy makers in the economic union by a hypothetical planner can support firms through the government budget and regulate the labor market through imposing an effective minimum wage for (unskilled) labor - either directly, or through supporting labor unions by legislation. Lobbies representing workers and firms attempt to influence the planner for prospective policy. Economic integration occurs, when the planner has an incentive to accept new regions (and consequently, new firms) as members to the union. In this set up, R\&D-based growth plays a crucial rule, for the labor market would be always fully deregulated in an equilibrium with no growth.

The growth effects of regulation depend decisively on the structure of economy. Where the same technology is used both in production and in $\mathrm{R} \& \mathrm{D}$, the economy behaves as if the same final good were used both in consumption and in $\mathrm{R} \& \mathrm{D}$. In that specific case, labor market regulation (e.g. the minimum wage) decreases profits, incentives to invest in $R \& D$ and the growth rate (cf. Peretto 1998). In this study, I assume that there is different technology for production and R\&D. ${ }^{1}$ With this specification, there can be a positive dependence between the minimum wage and technological change through cost-escaping $R \& D$ as follows. With higher wages, firms have more incentives to improve the productivity of labor through R\&D (cf. Palokangas 1996, 2000, 2004). This increases investment in R\&D and the growth rate.

\footnotetext{
${ }^{1}$ I take this to the extreme so that $R \& D$ employs only labor, for simplicity.
} 
There is also some empirical evidence on a positive relationship between R\&D and labor market regulation through high wages and unemployment. Caballero (1993) and Hoon and Phelps (1997) show that changes in unemployment and productivity growth are positively associated.

Except cost-escaping, there has been also other attempts to explain a positive wage-growth relationship. Cahuc and Michel (1996) (using an OLG model), as well as Agell and Lommerud (1997) (using an extensive game framework) show that minimum wages create an incentive for workers to accumulate human capital. Meckl's (2004) assumes efficiency wages for both production and R\&D and argues the following. The greater the size of the high-wage sector (e.g. the R\&D sector), the higher is unemployment generated by efficiency wages. On the other hand, the greater the relative size of the R\&D sector, the higher is the growth rate of the economy. Despite of these alternative explanations, I stick to cost-escaping, because it provides a direct link from rents to incentives to improve technology.

I organize the remainder of this study as follows. In section 2, I present the institutional setting of the study as an extended game. As a part of this game, I construct specific models for households in section 3, firms in 4 and for the economic union in 5. Finally, I analyze the political equilibrium in section 6 and economic integration in section 7 .

\section{The setting}

I consider an economic union that contains a number $J$ of similar regions. ${ }^{2}$ A member country of the union is comprised of a smaller number $(<J)$ of these regions. Each region $j \in\{1, \ldots, J\}$ possesses fixed amounts $L$ and $N$ of skilled and unskilled labor, respectively. ${ }^{3}$ To examine the political economy of growth and economic integration, the model is then composed as follows:

The firms produce consumption goods from skilled and unskilled labor. Oligopolistic competition among these determines prices in the union. Firms invest in R\&D to escape production costs. Only skilled labor is used in R\&D.

\footnotetext{
${ }^{2}$ The assumption on similar regions is admittedly strong, but with asymmetric regions there can be multiple equilibria in the model.

${ }^{3}$ With more complication, one obtains the same results on the assumption that unskilled workers are transformed into skilled at some cost. Cf. Section 4 in Palokangas (2005).
} 
The planner of the union accepts new members to the union, supports firms through taxation and regulates the labor market through imposing a minimum wage for unskilled labor. The planner is self-interested and it is lobbied by interest groups that represent workers and firms.

Income distribution can be changed in favor of profits by taxing labor input and distributing the tax revenue to firms in the form of lump-sum subsidies. I assume that the reversed policy intervention - subsidizing labor and financing this by setting lump-sum taxes on firms - is incentive incompatible. A firm receives happily a lump-sum transfer, but responds to a lump-sum tax easily by changing its juridical identity (e.g. by using subcontractors). This also explains why it is easier to change income distribution in favor of wages by minimum wages rather than subsidies.

Because a new member has access to the same technology and must adopt the same institutions as the old members, economic integration can be characterized by an increase in the size $J$ of the economic union. Such integration intensifies competition in the product market.

I use the common agency model (e.g. Bernheim and Whinston 1986, Grossman and Helpman 1994a, and Dixit, Grossman and Helpman 1997) to establish a political equilibrium with the following sequence of decisions:

1. Worker and employer lobbies make their offers to the planner (section 6 ). These offers relate the lobbies' prospective political contributions to the planner's policy.

2. The planner support firms, sets the minimum wage for unskilled labor and accepts new members to the economic union (Section 5).

3. Firms decide how much to invest in R\&D (Subsection 4.2).

4. Each firm decides on its output given its expectations on the behavior of the other firms (Subsection 4.1).

5. The households decide on their consumption (Section 3).

This extended game is solved by backward induction. 


\section{Output, consumption and labor supply}

\subsection{Production technology}

In each region $j \in\{1, \ldots, J\}$ of the economic union, a single firm (hereafter firm $j$ ) produces good $j$ from labor with technology

$$
y_{j}=B_{j} n_{j}
$$

where $y_{j}$ output, $n_{j}$ labor input in production and $B_{j}$ is the productivity parameter. I assume that all products $j \in\{1, \ldots, J\}$ are perfect substitutes, for simplicity. ${ }^{4}$ The total supply of the composite good in the economic union, $C$, is the sum of regional outputs $y_{j}$ :

$$
C=\sum_{j=1}^{J} y_{j} .
$$

The average productivity of the economic union is given by

$$
B \doteq \frac{1}{J} \sum_{j=1}^{J} B_{j} .
$$

Technology (1), (2) and (3) has the useful property that with symmetry throughout the regions, $n_{j}=n$ for all $j$, total consumption is determined by

$$
\left.C\right|_{n_{j}=n}=J n B
$$

Because consumption per region, $C / J$, is then independent of the size $J$ of the union, there are no scale effects on consumption. In this case, economic integration is motivated only by rents in the goods or labor market. ${ }^{5}$

\subsection{Households}

All households in the economic union share the same preferences and take income, the prices and the interest rate $r$ as given. Thus, they all behave

\footnotetext{
${ }^{4}$ With some complication, it is possible to use a CES function here for the same purpose.

${ }^{5}$ It would be easy to extend the model so that, in line with Ethier (1982), the number of firms, $J$, increases the productivity of each firm. In that case, the production function (1) would change into $y_{j}=\varpi(J) B_{j} n_{j}$, where $\varpi(J)$ is an increasing function of $J$. This would create an additional incentive for the planner of the union to increase the size of the union indefinitely, but without any change in the results.
} 
as if there were a single representative household for the whole economic union. The household chooses its flow of consumption $C$ to maximize its utility starting at time $T$,

$$
\int_{T}^{\infty}(\log C) e^{-\rho(\theta-T)} d \theta
$$

where $\theta$ is time, $C$ consumption and $\rho>0$ the constant rate of time preference. Noting (2), this utility maximization leads to the Euler equation ${ }^{6}$

$$
\dot{\mathcal{E}} / \mathcal{E}=r-\rho \quad \text { with } \quad \mathcal{E} \doteq p C=p \sum_{j=1}^{J} y_{j}
$$

where $p$ the consumption price, $\mathcal{E}$ total consumption expenditure, $r$ the interest rate and $\dot{\mathcal{E}}=d \mathcal{E} / d t$. Because in the model there is no money that would pin down the nominal price level at any time, it is convenient to normalize the households' total consumption expenditure in the economic union, $\mathcal{E}$, at the constant number $J$ of regions. ${ }^{7}$ This and (5) yield

$$
\mathcal{E}=J, \quad p=\mathcal{E} / \sum_{j=1}^{J} y_{j}=J / \sum_{j=1}^{J} y_{j}, \quad r=\rho=\text { constant }>0 .
$$

\subsection{The labor market}

Skilled labor is used both in production and R\&D, but unskilled labor only in production. I assume that technology in production is characterized by the CES unit cost function

$$
c\left(w_{j}, v_{j}\right), \quad c_{w}>0, \quad c_{v}>0, \quad c_{w w}<0, \quad c_{v v}<0, \quad c_{w v}>0
$$

where $v_{j}$ and $w_{j}$ are the wages for skilled and unskilled labor, respectively, and the subscripts $w$ and $v$ denote the partial derivatives with respect to $w_{j}$ and $v_{j}$, respectively. Following empirical evidence, I assume that the elasticity of substitution between skilled and unskilled labor is less than one:

$$
\frac{c c_{w v}}{c_{w} c_{v}}<1
$$

\footnotetext{
${ }^{6}$ Cf. Grossman and Helpman (1994b).

${ }^{7}$ With this normalization, the equilibrium price $p$ and the equilibrium wage $w$ are independent of the size of the economic union, $J$.
} 
The market for skilled labor is competitive, but I characterize labor market regulation by the assumption that the planner sets the minimum wage $w_{j}$ for unskilled labor. By duality, the equilibrium condition for the market of skilled labor and the full-employment constraint for unskilled labor can be constructed as follows:

$$
\begin{aligned}
& L=c_{v}\left(w_{j}, v_{j}\right) n_{j}+l_{j}=c_{v}\left(w_{j} / v_{j}, 1\right) n_{j}+l_{j}, \\
& N \geq c_{w}\left(w_{j}, v_{j}\right) n_{j}=c_{w}\left(w_{j} / v_{j}, 1\right) n_{j},
\end{aligned}
$$

where $n_{j}$ composite labor input in production, and $l_{j}$ labor input in R\&D.

\section{Firms}

\subsection{Production}

I assume that the planner of the economic union sets a $\operatorname{tax} \tau \geq 0$ on production costs $c\left(w_{j}, v_{j}\right) n_{j}$ and spends this money in paying a lump-sum subsidy $\gamma$ to all firms. The planner's budge constraint is therefore given by

$$
\gamma J=\tau \sum_{k=1}^{J} c\left(w_{k}, v_{k}\right) n_{k}
$$

Each firm $j$ maximizes its profit

$$
\pi_{j} \doteq p y_{j}-(1+\tau) c\left(w_{j}, v_{j}\right) n_{j}+\gamma,
$$

where $y_{j}$ is output, by its labor input $n_{j}$ holding the wages $\left(w_{j}, v_{j}\right)$, productivity $B_{j}$ and the other firms' output $\sum_{k \neq j} y_{k}$ constant, given the production function (1). There are two consequences of this profit maximization. Noting (6), the profit maximization yields the equilibrium condition

$$
(1+\tau) c\left(w_{j}, v_{j}\right)=\left[p+y_{j} \frac{d p}{d y_{j}}\right] \frac{\partial y_{j}}{\partial n_{j}}=\left[1-\frac{y_{j}}{\sum_{k=1}^{J} y_{k}}\right] p B_{j} .
$$

Because all firms $j=1, \ldots, J$ are similar, in equilibrium $y_{k}=y$ for all $k$ holds true. From this, (1), (12) and (13) it follows that

$$
\begin{aligned}
& (1+\tau) c\left(w_{j}, v_{j}\right)=(1-1 / J) p B_{j}, \quad(1+\tau) c\left(w_{j}, v_{j}\right) n_{j}=(1-1 / J) p y_{j} \\
& \pi_{j}=p y_{j}-(1+\tau) c\left(w_{j}, v_{j}\right) n_{j}+\gamma=p y_{j} / J+\gamma
\end{aligned}
$$


I assume that the planner holds the firms' income share $\sum_{k} \pi_{k} /\left(p \sum_{j} y_{j}\right)$ at its target level $\phi$ by the wage tax $\tau$. Given $\tau \geq 0$, (1) and (11), it is then true that $\gamma \geq 0$ and

$$
\begin{aligned}
& \phi=\sum_{k=1}^{J} \pi_{k} /\left(p \sum_{j=1}^{J} y_{j}\right)=\left[p \sum_{k=1}^{J} y_{k}-\sum_{k=1}^{J} c\left(w_{k}, v_{k}\right) n_{k}\right] /\left(p \sum_{j=1}^{J} y_{j}\right) \\
&=1-\sum_{k=1}^{J} c\left(w_{k}, v_{k}\right) n_{k} /\left(p \sum_{j=1}^{J} y_{j}\right), \\
& \sum_{j=1}^{J} c\left(w_{j}, v_{j}\right) n_{j}=(1-\phi) p \sum_{j=1}^{J} y_{j}=(1-\phi) J, \quad \sum_{j=1}^{J} \pi_{j}=\phi p \sum_{j=1}^{J} y_{j}=\phi J \\
& \phi=\sum_{k=1}^{J} \pi_{k} /\left(p \sum_{j=1}^{J} y_{j}\right)=\frac{1}{J}+\gamma /\left(p \sum_{j=1}^{J} y_{j}\right) \geq \frac{1}{J} .
\end{aligned}
$$

These results show that labor inputs in production, $n_{j}$, can be constant, provided that the wages $w_{j}$ and the profits $\pi_{j}$ change in the same proportion. Without this property, there were no steady state in the model. The firms' income share $\phi$ has a lower limit $1 / J$ that is determined by the size $J$ of the economic union.

\subsection{Research and development (R\&D)}

Technological change for firm $j$ is characterized by a Poisson process $q_{j}$ as follows. During a short time interval $d \theta$, there is an innovation $d q_{j}=1$ with probability $\Lambda_{j} d \theta$, and no innovation $d q_{j}=0$ with probability $1-\Lambda_{j} d \theta$, where $\Lambda_{j}$ is the arrival rate of innovations in the research process. The arrival rate $\Lambda_{j}$ is in fixed proportion $\lambda$ to labor devoted to $\mathrm{R} \& \mathrm{D}, l_{j}$,

$$
\Lambda_{j}=\lambda l_{j}, \quad \lambda>0
$$

I denote the serial number of technology in region $j$ by $t_{j}$ and variables depending on technology $t_{j}$ by superscript $t_{j}$. The invention of a new technology raises $t_{j}$ by one and the level of productivity $B_{j}^{t_{j}}$ by $a>1$. Hence,

$$
B_{j}^{t_{j}}=B_{j}^{0} a^{t_{j}} .
$$

During a short time interval $d \theta$, there is a change in technology from $t_{j}$ to $t_{j}+1$ with probability $\Lambda_{j} d \theta$, and no change with probability $1-\Lambda_{j} d \theta$, where 
$\Lambda_{j}$ is given by (15). The average growth rate of the level of productivity (16) in the stationary state is in fixed proportion $(\lambda \log a)$ to labor in $\mathrm{R} \& \mathrm{D}, l_{j}$ (cf. Aghion and Howitt 1998, p. 59). This leads to the following conclusion:

Proposition 1 Research input $l_{j}$ can be used as a proxy of the growth rate in region $j$ and the average research input $l=\frac{1}{n} \sum_{j=1}^{n} l_{j}$ as a proxy of the growth rate for the whole economic union.

Firm $j$ 's dividends are given by

$$
\Pi_{j}=\pi_{j}-v_{j} l_{j}
$$

where $\pi_{j}$ is profit, $v_{j}$ the skilled workers' wage, $l_{j}$ labor devoted to R\&D and $v_{j} l_{j}$ expenditures on $\mathrm{R} \& \mathrm{D}$ in region $j$. Firm $j$ maximizes the present value of its dividends (17) by its input to $\mathrm{R} \& \mathrm{D}, l_{j}$, subject to technological change, given the wage $v_{j}$. The value of firm $j$ 's optimal program at time $T$ is

$$
\Omega\left(t_{j}, v_{j}, \pi_{j}\right)=\max _{l_{j} \text { s.t. }(15),(17)} E \int_{T}^{\infty} \Pi_{j} e^{-r(\theta-T)} d \theta
$$

where $\theta$ is time, $E$ the expectation operator and $r$ the interest rate.

I consider a symmetric equilibrium where the initial productivity is the same, $B_{j}^{0}=B^{0}$ for all $j$, for tractability. In that case

$$
n_{j}=n, l_{j}=l, w_{j}=w, v_{j}=v, \pi_{j}=\pi \text { and } \Pi_{j}=\Pi \text { for } j=1, \ldots, J .
$$

In the Appendix, I prove the following:

$$
\begin{aligned}
& \Pi / \pi=1+(1-a) \lambda l / r, \quad v=(a-1) \lambda \pi / r, \\
& w / v=\Upsilon(\phi, l), \quad \partial \Upsilon / \partial \phi<0, \quad \partial \Upsilon / \partial l>0, \\
& n=\Delta(\phi, l), \quad \partial \Delta / \partial \phi>0, \quad \partial \Delta / \partial l<0, \\
& N \geq \Theta(\phi, l), \quad \partial \Theta / \partial \phi>0, \quad \partial \Theta / \partial l<0,
\end{aligned}
$$

where the inequality (22) is the new form of the full-employment constraint for unskilled labor, (10). 


\section{The economic union}

\subsection{Equilibrium in production and $R \& D$}

From (14) and (19) it follows that

$$
c(w, v) n=1-\phi, \quad \pi=\phi .
$$

By (1), (6), (19), (20) and (22), I define the present value of the expected flow of real income per region, y, as (cf. Aghion and Howitt 1998, p. 61)

$$
\begin{aligned}
\Psi(l, \phi) & \doteq E \int_{T}^{\infty} \frac{1}{p} e^{-r(\theta-T)} d \theta=E \int_{T}^{\infty}\left(\frac{1}{J} \sum_{j=1}^{J} y_{j}\right) e^{-r(\theta-T)} d \theta \\
& =E \int_{T}^{\infty} y e^{-r(\theta-T)} d \theta=E \int_{T}^{\infty} B n e^{-r(\theta-T)} d \theta=\frac{B(T) n}{r+(1-a) \lambda l} \\
& =\frac{B(T) \Theta(\phi, l)}{r+(1-a) \lambda l} \quad \text { with } \quad \frac{\partial \Psi}{\partial \phi}>0
\end{aligned}
$$

From (21) and (23) it follows that

$$
(1-\phi) / w=c(1, v / w) n=c(1,1 / \Upsilon(\phi, l)) \Delta(\phi, l) .
$$

Differentiating the logarithm of this equation totally, and noting (21), one obtains that skilled labor devoted to $\mathrm{R} \& \mathrm{D}, l$, is an increasing function of the minimum wage for unskilled labor, $w$ :

$$
\frac{d l}{d w}=\underbrace{\frac{c_{v}}{c \Upsilon 2}}_{+} \underbrace{\frac{\partial \Upsilon}{\partial l}}_{+}-\underbrace{\frac{1}{\Delta}}_{+} \underbrace{\frac{\partial \Delta}{\partial l}}_{-}>0 .
$$

\subsection{The worker and employer lobbies}

The workers and the firms lobby the planner which decides on the firms' income share $\phi \geq 1 / J$, the minimum wage $w$ for unskilled labor and new members of the economic union (i.e. the size $J$ of the union), given (22). Noting the one-to-one correspondence (25), the minimum wage $w$ can be replaced by labor devoted to $R \& D, l$, as the state variable. The constraints for the state variables $(l, \phi, J)$ of the lobbying equilibrium are given by $\phi \geq$ $1 / J$ and the full-employment constraint (22). 
I assume that all unskilled workers $N J$ plus a given proportion $\alpha \in[0,1]$ of skilled workers $L J$ in the union belong to the worker lobby. The wages in the economic union are equal to total labor costs in production, $c(w, v) n J$, plus those in $\mathrm{R} \& \mathrm{D}, v l J$. This implies that the total income of the members of the worker lobby is equal to $c(w, v) n J+v l J-(1-\alpha) v L J$, where $(1-\alpha) v L J$ is the income of those skilled workers who do not belong to the worker lobby. Dividing this by the number of regions, $J$, we obtain the typical members' income in the worker lobby as $c(w, v) n+v l-(1-\alpha) v L$.

All firms belong to the employer lobby and they earn dividends $\Pi J$. Dividing this by the number of regions, $J$, we obtain the typical members' income in the employer lobby as $\Pi$.

Following Grossman and Helpman (1994a), I assume that the planner has its own interests and collects contributions $R_{u}$ and $R_{f}$ from the worker and employer lobbies. A typical member of the worker lobby earns its income $c(w, v) n+v l-(1-\alpha) v L$ minus political contributions $R_{u}$. A typical member of the employer lobby earn its income $\Pi$ minus political contributions $R_{f}$. Because the effects through the the price level $p$ can be internalized at the level of the economic union, the worker lobby maximizes the present value $\mathcal{U}$ of the expected flow of a typical worker's real income

$$
\left[c(w, v) n+v l-(1-\alpha) v L-R_{u}\right] / p,
$$

and the employer lobby maximizes the present value $\mathcal{F}$ of the expected flow of a typical firm's real income $\left(\Pi-R_{f}\right) / p$ at time $T$. Noting $(20),(23)$ and (24), these targets can be defined as follows:

$$
\begin{aligned}
\mathcal{U}\left(l, \phi(J, \varphi), R_{u}\right) & \doteq E \int_{T}^{\infty} \frac{c(w, v) n+v l-(1-\alpha) v L-R_{u}}{p} e^{-r(\theta-T)} d \theta \\
& =\Psi\left[c(w, v) n+v l-(1-\alpha) v L-R_{u}\right] \\
& =\Psi\left\{c(w, v) n+[l-(1-\alpha) L] v-R_{u}\right\} \\
& =\Psi\left\{1-\phi+[l-(1-\alpha) L](a-1) \lambda \pi / r-R_{u}\right\} \\
& =\Psi(l, \phi)\left\{1-\phi+[l-(1-\alpha) L](a-1) \lambda \phi / r-R_{u}\right\}, \\
\mathcal{F}\left(l, \phi(J, \varphi), R_{u}\right) & \doteq E \int_{T}^{\infty} \frac{\Pi-R_{f}}{p} e^{-r(\theta-T)} d \theta=\Psi\left[\Pi-R_{f}\right] \\
& =\Psi\left\{[1+(1-a) \lambda l / r] \pi-R_{f}\right\},
\end{aligned}
$$


where

$$
\mathcal{U}\left(l, \phi, R_{f}\right)+\mathcal{F}\left(l, \phi, R_{f}\right)=\left[1-R_{u}-R_{f}-(1-\alpha)(a-1) \lambda L \phi / r\right] \Psi(l, \phi) .
$$

\subsection{The self-interested planner}

Noting (24), the present value the expected flow of the real political contributions at time $T$ is given by

$$
E \int_{T}^{\infty} \frac{R_{u}+R_{f}}{p} e^{-r(\theta-T)} d \theta=\Psi(l, \phi)\left(R_{u}+R_{f}\right) .
$$

Given this and (28), I specify the planner's utility function as follows:

$$
\begin{aligned}
& G\left(l, \phi(J, \varphi), R_{u}, R_{f}\right)=G\left(l, \phi, R_{u}, R_{f}\right) \\
& \doteq E \int_{T}^{\infty} \frac{R_{u}+R_{f}}{p} e^{-r(\theta-T)} d \theta+\zeta_{w} \mathcal{U}\left(l, \phi, R_{u}\right)+\zeta_{f} \mathcal{F}\left(l, \phi, R_{f}\right) \\
& =\Psi(l, \phi)\left(R_{u}+R_{f}\right)+\zeta_{w} \mathcal{U}\left(l, \phi, R_{u}\right)+\zeta_{f} \mathcal{F}\left(l, \phi, R_{f}\right) \\
& =[\underbrace{[-(1-\alpha)(a-1) \lambda L \phi / r}_{+}] \Psi(l, \phi) \\
& \quad+\left(\zeta_{w}-1\right) \mathcal{U}\left(l, \phi, R_{u}\right)+\left(\zeta_{f}-1\right) \mathcal{F}\left(l, \phi, R_{f}\right),
\end{aligned}
$$

where constants $\zeta_{w} \geq 0$ and $\zeta_{f} \geq 0$ are weights of the worker's and the firm's welfare in the government's preferences, respectively.

Grossman and Helpman's (1994a) objective function (30) is widely used in models of common agency and it has been justified as follows. The politicians are mainly interested in their own income which consists of the contributions from the public, $R_{u}+R_{f}$, but because they must defend their position in general elections, they must sometimes take the utilities of the interest groups $\mathcal{U}\left(l, \phi, R_{u}\right)$ and $\mathcal{F}\left(l, \phi, R_{f}\right)$ into account directly. The linearity of (30) in $\Psi\left[R_{u}+R_{f}\right]$ is assumed, for simplicity.

\section{The political equilibrium}

The workers' and employers' lobbies try to affect the planner by their contributions $R_{u}$ and $R_{f}$. The contribution schedules are therefore functions of 
the planner's policy variables:

$$
R_{u}(l, \phi), \quad R_{f}(l, \phi)
$$

The planner maximizes its utility function $(30)$ by $(l, \phi)$, given the contribution schedules (31) and the constraints $\phi \geq 1 / J$ and (22). Following proposition 1 of Dixit, Grossman and Helpman (1997), a subgame perfect Nash equilibrium for this game is a set of contribution schedules $R_{u}(l, \phi)$ and $R_{f}(l, \phi)$ and policy $(l, \phi)$ such that the following conditions $(i)-(i v)$ hold:

(i) Contributions $R_{u}$ and $R_{f}$ are non-negative but no more than the contributor's income.

(ii) The policy $(\phi, l)$ maximizes the planner's welfare (30) taking the contribution schedules $R_{u}$ and $R_{f}$ as given,

$$
(l, \phi) \in \arg \max _{(l, \phi) \text { s.t. } \phi \geq 1 / J \text { and }(22)} G\left(l, \phi, R_{u}(l, \phi), R_{f}(l, \phi)\right)
$$

(iii) The worker lobby (employer lobby) cannot have a feasible strategy $R_{u}(l, \phi)\left(R_{f}(l, \phi)\right)$ that yields it a higher level of utility than in equilibrium, given the planner's anticipated decision rule,

$$
\begin{aligned}
& (l, \phi)=\arg \max _{(l, \phi) \text { s.t. } \phi \geq 1 / J \text { and }(22)} \mathcal{U}\left(l, \phi, R_{u}(l, \phi)\right), \\
& (l, \phi)=\arg \max _{(l, \phi) \text { s.t. } \phi \geq 1 / J \text { and }(22)} \mathcal{F}\left(l, \phi, R_{f}(l, \phi)\right) .
\end{aligned}
$$

(iv) The worker lobby (employer lobby) provides the planner at least with the level of utility than in the case it offers nothing $R_{u}=0\left(R_{f}=0\right)$, and the planner responds optimally given the other lobby's contribution function,

$$
\begin{aligned}
& G\left(l, \phi, R_{u}(l, \phi), R_{f}(l, \phi)\right) \geq \max _{(l, \phi) \text { s.t. } \phi \geq 1 / J \text { and }(22)} G\left(l, \phi, R_{u}(l, \phi), 0\right), \\
& G\left(l, \phi, R_{u}(l, \phi), R_{f}(l, \phi)\right) \geq \max _{(l, \phi) \text { s.t. } \phi \geq 1 / J \text { and }(22)} G\left(l, \phi, 0, R_{f}(l, \phi)\right) .
\end{aligned}
$$


Noting (31) and (32), the planner's utility function (30) changes into

$$
\begin{aligned}
\mathcal{G}(l, \phi) \doteq & G\left(l, \phi, R_{u}(l, \phi), R_{f}(l, \phi)\right) \\
= & \Psi(l, \phi)+\left(\zeta_{w}-1\right) \operatorname{ll}_{(l, \phi) \text { s.t. } \phi \geq 1 / J \text { and }(22)} \mathcal{U}\left(l, \phi, R_{u}(l, \phi)\right) \\
& +\left(\zeta_{f}-1\right) \max _{(l, \phi) \text { s.t. }} \max _{\phi \geq 1 / J \text { and }(22)} \mathcal{F}\left(l, \phi, R_{f}(l, \phi)\right), \\
\frac{\partial \mathcal{G}}{\partial l}= & {[\underbrace{1-(1-\alpha)(a-1) \frac{\lambda}{r} L \phi}_{+}] \frac{\partial \Psi}{\partial l}, } \\
\frac{\partial \mathcal{G}}{\partial \phi}= & {[\underbrace{1-(1-\alpha)(a-1) \frac{\lambda}{r} L \phi}_{+}] \frac{\partial \Psi}{\partial \phi}-\underbrace{(1-\alpha)(a-1) \frac{\lambda}{r} L \Psi}_{+} . }
\end{aligned}
$$

The Lagrangean for the maximization of the planner's utility function (33) by $(l, \phi)$ subject to the elasticity constraint $\phi \geq 1 / J$ and the full-employment constraint (22) is given by

$$
\mathcal{H}=\mathcal{G}(l, \phi)+\eta[\phi-1 / J]+\varepsilon[N-\Theta(\phi, l)],
$$

where the multipliers $\varepsilon$ and $\vartheta$ are subject to the Kuhn-Tucker conditions

$$
\eta[\phi-1 / J]=0, \quad \eta \geq 0, \quad \varepsilon[N-\Theta(\phi, l)]=0, \quad \varepsilon \geq 0 .
$$

Noting (22), (24), (33) and (34), the first-order conditions for the maximization of the planner's utility are the following:

$$
\frac{\partial \mathcal{H}}{\partial \phi}=\frac{\partial \mathcal{G}}{\partial \phi}+\eta-\varepsilon \frac{\partial \Theta}{\partial \phi}=0, \quad \frac{\partial \mathcal{H}}{\partial l}=\frac{\partial \mathcal{G}}{\partial l}-\varepsilon \frac{\partial \Theta}{\partial l}=0 .
$$

\section{Economic integration}

If the size of the union, $J$, is small, then $\phi=1 / J$. In that case, by (34) and (35), $\eta>0$ and $\partial \mathcal{H} / \partial J=\eta / J^{2}>0$ hold true. If the union is large enough, $J>1 / \phi$, then, and by (24), (35) and (36), it is true that

$$
\phi>\frac{1}{J}, \quad \eta=0, \quad \varepsilon=\frac{\partial \mathcal{G}}{\partial \phi} / \frac{\partial \Theta}{\partial \phi}>0, \quad N=\Theta
$$

and $\partial \mathcal{H} / \partial J=\eta / J^{2} \equiv 0$. These results can be rephrased as follows: 
Proposition 2 The planner has no incentives to prevent integration (i.e. the increase of $J), \partial \mathcal{H} / \partial J=\eta / J^{2} \geq 0$. In a small union, the firms are not supported $(\tau=0$ and $\phi=1 / J)$. In a large union, the firms are supported $(\tau>0$ and $\phi>1 / J)$ and the labor market is deregulated $(\Theta=N)$.

Both current income and the growth rate increase the planner's welfare. Because integration increases competition and improves efficiency, it does not harm the planner. Since competition increases the demand for labor in production, then, in a large union, a large proportion of labor is devoted to production and only a small proportion to $R \& D$. Because this leaves very little space for R\&D and economic growth, the planner must start supporting firms. Because this boosts economic growth, labor market regulation is no more needed for that purpose. Consequently, in a large union, the labor market is deregulated to increase current income.

In a small economic union with no support to firms, $\phi=1 / J$, noting (22), (24), (33), (35) and (36), there are two possibilities:

(a) The present value of the expected flow of real income, $\Psi$, does not attain its maximum in the unemployment regime:

$$
\frac{\partial \Psi}{\partial l}<0, \quad \frac{\partial \mathcal{G}}{\partial l}<0, \quad \Theta(1 / J, l)=N, \quad \varepsilon=\underbrace{\frac{\partial \Psi}{\partial l}}_{-} / \underbrace{\frac{\partial \Theta}{\partial l}}_{-}>0 .
$$

In that case, the labor market is deregulated (i.e. unemployment).

(b) The present value of the expected flow of real income, $\Psi$, attains its maximum in the unemployment regime: $\Theta<N, \varepsilon=0$,

$$
\frac{\partial \Psi}{\partial l}=0, \quad \frac{\partial \mathcal{G}}{\partial l}=0, \quad 0=\frac{\partial \log \Psi}{\partial l}=\underbrace{\frac{1}{n}}_{+} \underbrace{\frac{\partial \Theta}{\partial l}}_{-}+\underbrace{\frac{(\overbrace{a-1}^{+}) \lambda}{r+(1-a) \lambda l}}_{+} .
$$

In that case, the labor market is regulated (i.e. full employment).

Together with Proposition 2, these results can be rephrased as follows:

Proposition 3 In a small union, the firms are not supported and the labor market is either deregulated or regulated. When the labor market regulated, economic integration will reverse this at some stage so that the firms are supported and the labor market deregulated. 


\section{Conclusions}

This paper examines an economic union with a large number of regions, each producing a different good. The union expands by integrating new regions. Firms improve their productivity through investment in $R \& D$. The less there are firms in the union, the more they earn profits. Both workers and firms lobby the planner which determines the minimum wage for unskilled workers and the firms' market power and decides on new members to the union. The main findings of the paper can be summarized the follows.

In a small union, there is a little competition and large profits. In that case, there is political pressure on the planner to transfer income from the firms to the workers through the minimum wage for the unskilled labor. Since competition increases the demand for labor in production, then, in a large union, a large proportion of labor is devoted to production and only a small proportion to $R \& D$. Because this leaves very little space for $R \& D$, the economic growth rate falls, and the planner will be subject to political pressure to start supporting firms and to relax labor market regulation.

\section{Appendix}

From (14) and (16) it follows that

$$
\pi_{j}^{t_{j}+1} / \pi_{j}^{t_{j}}=B_{j}^{t_{j}+1} / B_{j}^{t_{j}}=a .
$$

The Bellman equation corresponding to (18) is given by ${ }^{8}$

$$
\begin{aligned}
& r \Omega\left(t_{j}, v_{j}, \pi_{j}\right)=\max _{l_{j}}\left\{\Pi_{j}+\Lambda_{j}\left[\Omega\left(t_{j}+1, v_{j}, \pi_{j}\right)-\Omega\left(t_{j}, v_{j}, \pi_{j}\right)\right]\right\} \\
& =\max _{l_{j}}\left\{\pi_{j}-v_{j} l_{j}+\lambda l_{j}\left[\Omega\left(t_{j}+1, v_{j}, \pi_{j}\right)-\Omega\left(t_{j}, v_{j}, \pi_{j}\right)\right]\right\} .
\end{aligned}
$$

The first-order condition corresponding to this is given by

$$
\lambda\left[\Omega\left(t_{j}+1, v_{j}, \pi_{j}\right)-\Omega\left(t_{j}, v_{j}, \pi_{j}\right)\right]=v_{j} .
$$

I try the solution

$$
\Pi_{j}=\beta_{j} \pi_{j}, \quad \beta_{j} \in(0,1), \quad \Omega=\Pi_{j} / \delta_{j},
$$

\footnotetext{
${ }^{8}$ cf. Dixit and Pindyck (1994), Wälde (1999).
} 
in which dividends $\Pi_{j}$ is in fixed proportion $\beta_{j}$ to profits $\pi_{j}$, and the subjective discount factor $\delta_{j}>0$ is independent of income $\pi_{j}$. Given (37) and (40), one obtains

$$
\widetilde{\Omega} \doteq \Omega\left(t_{j}+1, v_{j}, \pi_{j}\right)=\beta_{j} \pi_{j}^{t_{j}+1} / \delta_{j}=a \beta_{j} \pi_{j}^{t_{j}} / \delta_{j}=a \Omega\left(t_{j}, v_{j}, \pi_{j}\right) .
$$

Inserting this and (40) into (38), one obtains

$$
r=\Pi_{j} / \Omega+\lambda l_{j}(\widetilde{\Omega} / \Omega-1)=\delta_{j}+(a-1) \lambda l_{j}
$$

and

$$
\delta_{j}=r+(1-a) \lambda l_{j}>0 .
$$

From (40) and (17) it follows that

$$
v_{j} l_{j}=\pi_{j}-\Pi_{j}=\left(1 / \beta_{j}-1\right) \Pi_{j}=\left(1-\beta_{j}\right) \pi_{j} .
$$

Inserting (40), (41), (42) and (43) into (39), one obtains

$$
\begin{aligned}
(a-1) \lambda & =\lambda(\widetilde{\Omega} / \Omega-1)=v_{j} / \Omega=v_{j} \delta_{j} / \Pi_{j}=\left(1 / \beta_{j}-1\right) \delta_{j} / l_{j} \\
& =\left(1 / \beta_{j}-1\right)\left[r / l_{j}+(1-a) \lambda\right] .
\end{aligned}
$$

Noting (15), (40), (42), this equation defines the function

$$
\Pi_{j} / \pi_{j}=\beta_{j}=1+(1-a) \lambda l_{j} / r>0 .
$$

Inserting this into (43) yields

$$
v_{j}=\left(1-\beta_{j}\right) \pi_{j} / l_{j}=(a-1) \lambda \pi_{j} / r .
$$

In the symmetric equilibrium (19), noting (7), (14), (43) and (44), one obtains

$$
\begin{aligned}
n & =\left(\frac{1}{\phi}-1\right) \frac{\pi}{c(w, v)}=\left(\frac{1}{\phi}-1\right) \frac{\pi}{v} \frac{v}{c(w, v)}=\frac{(1 / \phi-1) l}{1-\beta} \frac{v}{c(w, v)} \\
& =\frac{1 / \phi-1}{(a-1) \lambda} \frac{r}{c(w / v, 1)} .
\end{aligned}
$$

This implies

$$
\log n=\log (1-\phi)-\log \phi-\log c(w / v, 1)-\log [(a-1) \lambda / r] .
$$


Differentiating the full-employment condition for skilled labor, (19), and equation (46) totally, one obtains

$$
\left(\begin{array}{cc}
n c_{w v} & c_{v} \\
c_{w} / c & 1 / n
\end{array}\right)\left(\begin{array}{c}
d(w / v) \\
d n
\end{array}\right)=-\left(\begin{array}{cc}
1 & 0 \\
0 & 1 /[(1-\phi) / \phi]
\end{array}\right)\left(\begin{array}{c}
d l \\
d \phi
\end{array}\right),
$$

where, by (8), it is true that

$$
\mathcal{A} \doteq\left|\begin{array}{cc}
n c_{w v} & c_{v} \\
c_{w} / c & 1 / n
\end{array}\right|=c_{w v}-\frac{c_{w} c_{v}}{c}=\underbrace{\frac{c_{w} c_{v}}{c c_{w v}}}_{+}[\underbrace{\left.\frac{c c_{w v}}{c_{w} c_{v}}-1\right]}_{-}<0 .
$$

This defines the functions

$$
\begin{aligned}
& \frac{w}{v}=\Upsilon(\phi, l), \quad \frac{\partial \Upsilon}{\partial \phi}=\frac{c_{v}}{(1-\phi) \phi \mathcal{A}}<0, \quad \frac{\partial \Upsilon}{\partial l}=-\frac{1}{n \mathcal{A}}>0, \\
& n=\Delta(\phi, l), \quad \frac{\partial \Delta}{\partial \phi}=-\frac{n c_{w v}}{(1-\phi) \phi \mathcal{A}}>0, \quad \frac{\partial \Delta}{\partial l}=\frac{c_{w}}{c \mathcal{A}}<0 .
\end{aligned}
$$

Given (47), the full-employment constraint (10) changes into

$$
\begin{aligned}
& N \geq c_{w}(\Upsilon(\phi, l), 1) \Delta(\phi, l) \doteq \Gamma(\phi, l) \doteq \Theta(\phi, l), \\
& \frac{\partial \Theta}{\partial \phi}=\underbrace{c_{w w}}_{-} \underbrace{\frac{\partial \Upsilon}{\partial \phi}}_{-}+\underbrace{c_{w}}_{+} \underbrace{\frac{\partial \Delta}{\partial \phi}}_{+}>0, \quad \frac{\partial \Theta}{\partial l}=\underbrace{c_{w w}}_{-} \underbrace{\frac{\partial \Upsilon}{\partial l}}_{+}+\underbrace{c_{w}}_{+} \underbrace{\frac{\partial \Delta}{\partial l}}_{-}<0 .
\end{aligned}
$$

Results (44), (45), (47), (48) and (49) prove (20) and (22).

\section{References:}

Acemoglu, D., Aghion, P. and Violante G.L. (2001). "Deunionzation, Technical Change and Inequality." Carnegie-Rochester Conference Series on Public Policy 55: 229-264.

Agell, J. and Lommerud, K.J. (1997). "Minimum Wages and the Incentives for Skill Formation." Journal of Public Economics 64: 25-40.

Aghion, P. and Howitt, P. (1998). Endogenous Growth Theory. Cambridge (Mass.): MIT Press.

Bernheim, D. and Whinston, M.D. (1986). "Menu auctions, resource allocation, and economic influence." Quarterly Journal of Economics 101: 1-31.

Binmore, K., Rubinstein, A. and Wolinsky, A. (1986). "The Nash Bargaining Solution in Economic Modelling." Rand Journal of Economics 1\%: 176-188. 
Caballero, R. (1993). "Comment on Bean and Pissarides." European Economic Review 37: 855-859.

Cahuc, P. and Michel, P. (1996). "Minimum Wage Unemployment and Growth." European Economic Review 40: 1463-1482.

Dixit, A., Grossman, G.M. and Helpman, E. (1997). "Common agency and coordination: general theory and application to management policy making." Journal of Political Economy 105: 752-769.

Dixit, A. and Pindyck, K. (1994). Investment under Uncertainty. Princeton: Princeton University Press.

Ethier, W. (1982). "National and international returns to scale in the modern theory of international trade." American Economic Review 71: 389-405.

Grossman, G.M. and Helpman, E. (1994a). "Protection for sale." American Economic Review 84: 833-850.

Grossman, G. and Helpman, E. (1994b). Innovation and Growth. Cambridge (Mass.): The MIT Press.

Hoon, H. T., and E. S. Phelps (1997). "Growth, Wealth, and the Natural Rate: Is Europe's Job Crisis a Growth Crisis?" European Economic Review 41: 549-557.

Meckl, J. (2004). "Accumulation of Technological Knowledge, Wage Differentials, and Unemployment." Journal of Macroeconomics 26: 65-82.

Palokangas, T. (1996). "Endogenous Growth and Collective Bargaining." Journal of Economic Dynamics and Control 20: 925-944.

Palokangas, T. (2000). Labour Unions, Public Policy and Economic Growth. Cambridge (U.K.): Cambridge University Press.

Palokangas, T. (2004). "Union-firm Bargaining, Productivity Improvement and Endogenous Growth." Labour: Review of Labour Economics and Industrial Relations 18: 191-205.

Palokangas, T. (2005). "International Labour Union Policy and Growth with Creative Destruction." Review of International Economics 13: 90-105.

Peretto, P.F. (1998). "Market Power, Growth and Unemployment." Duke Economics Working Paper 98-16.

Wälde, K. (1999). "A Model of Creative Destruction with Undiversifiable Risk and Optimizing Households." The Economic Journal 109: C156-C171. 